$$
\text { CONF-970135-4 }
$$

\title{
Long-Term Simulation of \\ OSTI Turbulence-Induced Loads Using the SNLWIND-3D, FAST, YawDyn, and ADAMS Numerical Codes
}

Neil D. Kelley

Alan D. Wright

Marshall L. Buhl, Jr.

James L. Tangler

Prepared for

1997 ASME Wind Energy Symposium

Reno, Nevada

January 6-9, 1997

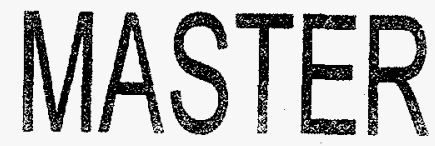

Nov 201996 


\section{NOTICE}

This report was prepared as an account of work sponsored by an agency of the United States government. Neither the United States government nor any agency thereof, nor any of their employees, makes any warranty, express or implied, or assumes any legal liability or responsibility for the accuracy, completeness, or usefulness of any information, apparatus, product, or process disclosed, or represents that its use would not infringe privately owned rights. Reference herein to any specific commercial product, process, or service by trade name, trademark, manufacturer; or otherwise does not necessarily constitute or imply its endorsement, recommendation, or favoring by the United States govemment or any agency thereof. The views and opinions of authors expressed herein do not necessarily state or reflect those of the United States government or any agency thereof.

Available to DOE and DOE contractors from:

Office of Scientific and Technical Information (OSTI)

P.O. Box 62

Oak Ridge, TN 37831

Prices available by calling (423) 576-8401

Available to the public from:

National Technical Information Service (NTIS)

U.S. Department of Commerce

5285 Port Royal Road

Springfield, VA 22161

(703) $487-4650$ 


\section{DISCLAMMER}

Portions of this document may be illegible in electronic image products. Images are produced from the best available original document. 


\title{
LONG-TERM SIMULATION OF TURBULENCE-INDUCED LOADS USING THE SNLWIND-3D, FAST, YAWDYN, AND ADAMS* NUMERICAL CODES ${ }^{\dagger \dagger}$
}

\author{
Neil D. Kelley \\ Alan D. Wright \\ Marshall L. Buhl, Jr. \\ James L. Tangler \\ National Wind Technology Center \\ National Renewable Energy Laboratory \\ Golden, Colorado 80401
}

\begin{abstract}
Notable progress was made in simulating the dynamic response of operating wind turbines during the past several years. In concert with these activities, the ability to adequately simulate the characteristics of the turbulent inflow, which is directly or indirectly responsible for much of the observed response, has also improved significantly. Recent investigations have shown that without such inflow simulations, it is often difficult to predict fatigue-load distributions that agree with observations. In this paper we discuss the results of a numerical experiment in which we simulated representative diurnal variations in the inflow environments for two distinct locations within a multi-row wind farm: upwind of the first and downwind of the last row of turbines. With the SNLWIND-3D turbulence simulation code, we created a series of 144,10 -minute inflow records that are likely to occur individually within a 24hour period at each location. An upwind, rigid-hub, three-bladed turbine was modeled with the Yaw Dynamics (YawDyn) and Automatic Dynamic Analysis of Mechanical Systems (ADAMS) simulation codes while a downwind, teetered-hub, two-bladed turbine was simulated with the Fatigue, Aerodynamics, Structures, and Turbulence (FAST) code and ADAMS. We found good to excellent agreement between the codes themselves in predicting the flapwise bending load spectra, and with limited test data.
\end{abstract}

\section{INTRODUCTION}

During the past several years, considerable progress was made in simulating the dynamic response of operating wind turbines. Part of this progress can be attributed to the ability to more realistically simulate the three-dimensional structure of the turbulent inflow. Recent investigations (Laino and Kelley ${ }^{1}$, and Wright, Kelley, and $\mathrm{Bir}^{2}$ ) showed that without such inflow simulations, it is difficult to predict load distributions for fatigue calculations that agree with observations. The situation is particularly acute for turbines operating within multi-row wind farms. Further, the need to more accurately specify the expected range of alternating loads under a wide range of operating environments for the purpose of design certification will undoubtedly involve the increased use of analytical simulations.

We view the development of the analytical simulations of wind turbine dynamics as an integrating factor all of our knowledge of these machines. Embodied in these codes is our analytical knowledge about the complex dynamics associated with wind turbines and their operating environments. We therefore decided to perform an extended numerical experiment to compare the calculated responses of analytical codes that we are currently using at the National Renewable Energy Laboratory's (NREL's) National Wind Technology Center (NWTC) to long-term (as opposed to only a few specific conditions) simulated inflows. To accomplish this, we used two reasonably validated turbine design models - a three-bladed, rigid hub and a two-bladed, teetered hub - using the available codes. These codes were the Yaw Dynamics (YawDyn), Fatigue, Aerody-

\footnotetext{
* ADAMS is a registered trademark of Mechanical Dynamics, Inc.

This work is supported by the U.S. Department of Energy under Contract DE-AC36-83CH10093.

₹ This paper is declared a work of the U.S. Government and is not subject to copyright protection in the United States.
} 
namics, Structures, and Turbulence (FAST), and Automatic Dynamic Analysis of Mechanical Systems (ADAMS), and the turbulence simulator SNLWIND3D.

In previous work, Kelley ${ }^{3}$ showed that the alternating load distribution seen on a three-bladed, rigid hub turbine could be described as a linear sum of three parametric statistical distributions. Initially it was thought that the low-cycle, high-amplitude or LCHA region (high-loading tail) of the spectrum could be described by a lognormal distribution. Upon closer examination of this and load spectra from other turbines it was found, for return frequencies less than about 100 cycles $h$, that a decaying exponential distribution provided a better paradigm (except for the root edgewise bending where an extreme value distribution was found to be appropriate) (Kelley ${ }^{4.5}$ ). The majority of the fatigue damage in rotor blades made of composite materials occurs in the LCHA region (Winterstein and Lange ${ }^{6}$. Kelley ${ }^{4}$ has suggested that the asymptotic behavior seen in the LCHA load range is possibly a consequence of the process being Poisson (i.e., the turbulent inflow events responsible for the load cycle peaks and valleys being independent of one another). Further work is required to establish a causal relationship. Kelley ${ }^{4}$ also demonstrated that the shape parameter or slope of the LCHA-range exponential distribution was highly correlated with the turbulent inflow scaling parameters of hub-height (local) friction velocity or $\left(\mathrm{u}_{*}\right)^{*}$ and the static stability expressed as the gradient Richardson number ( $\mathrm{Ri})^{\text {)"t }}$

The objectives of this experiment have been to assess the ability of the simulations to:

- Reproduce the shape of the observed alternating-load distributions; i.e., an exponential decay in the very damaging tail or Low-Cycle, HighAmplitude (LCHA) load region

- Exhibit the sensitivity of the slope (fatiguedamage potential) of this exponential distribution to the turbulent inflow parameters of hub-height mean turbulent shearing stress or local friction velocity $\left(\mathrm{u}_{*}\right)$ and vertical stability (Richardson number, $\mathrm{Ri}$ )

- Determine how well the predicted, alternatingflapwise, load spectra compare with available measurements for each turbine design.

$s_{u *} \equiv{\overline{\left(-u^{\prime} w^{\prime}\right)}}^{1 / 2}$ where $u^{\prime}$ and $w^{\prime}$ are the zero-mean longitudinal and vertical wind components.

${ }^{* *} \mathrm{Ri}=(\mathrm{g} / \theta)(\partial \theta / \partial \mathrm{z}) /(\partial \mathrm{U} / \partial \mathrm{z})^{2}$ where $\mathrm{g}$ is the gravity acceleration, $\theta=\mathrm{T}(1000 / \mathrm{p})^{.286}, \mathrm{~T}$ is the absolute temperature, $\mathrm{U}$ is the wind speed, $\mathrm{z}$ is the height. and $\mathrm{p}$ is the barometric pressure.

\section{APPROACH}

Our approach was to simulate, using the SNLWIND-3D code, 144, 10-minute inflow records or 24 hours of representative turbulent inflow conditions that are likely to been seen immediately upstream and downstream of a large, 41-row wind farm in San Gorgonio Pass, California. These simulations are based on boundary-layer measurements taken from two extensively instrumented, $50-\mathrm{m}$ meteorological towers installed at these locations during June, July, and August of the 1989 wind season. At that time, there were no wind turbines installed immediately upwind of Row 01 of the wind farm and the tower. The upwind terrain is very smooth consisting of low, rolling sand hills or dunes, but is confined by the abruptly rising and complex landforms of the pass in the crosswind directions. The downwind tower was located immediately behind Row 41, with the closest operating turbine located two rows, or 14 rotor diameters (D), upstream. At that time there were more than 900 turbines installed between Rows 01 and 41 of this wind farm.

We used each of the 10-minute inflow simulations for each location as input to the numerical simulations of each turbine to predict time-load histories for various parameters depending on the specific dynamics code involved. In this paper, however, we have confined our discussion to the root flapwise bending moments, because this parameter is quite sensitive to the dynamics of the turbulence/turbine interaction. The three-bladed, rigid-hub turbine (Micon 65/13) was simulated using existing YawDyn and ADAMS models. The twobladed, teetered-hub turbine was simulated using the two-bladed version of the FAST code (called FAST2) and by ADAMS

The same inflow was used to excite each turbine model for each of the two locations, allowing us to not only compare the relative response characteristics of each of the simulation codes for the same input to the same turbine, but also to determine some general indications about how each of the designs responds compared with each other. The predicted flapwise loadtime history for each turbine blade was rainflow-cycle counted over each individual 10 -minure record and from a single series 24 hours in length derived by concatenating the 144 individual records. The alternating load spectra from each blade were then summed into a single alternating load distribution for analysis. We then compared the resulting distributions with respect to the shape of the high loading tails and with available observations. The potential impact on low-cycle behavior as a result of the rainflow cycle-counting of long, discontinuous load histories that have been concatenated is discussed in Kelley and Sutherland? 


\section{SIMULATION MODELS USED}

A total of five numerical codes were used in this experiment. These included the SNLWIND-3D turbulent inflow simulation and specific turbine models using the YawDyn (simple), FAST2 (moderately complex), and ADAMS (complex) structural dynamics codes. We linked AeroDyn Version 9.3 to the three structural codes. We will now briefly describe each of the five codes.

\section{SNLWIND-3D}

This code represents an expansion of the original stochastic wind simulator, SNLWIND, developed by Veers ${ }^{\mathrm{x}}$. SNLWIND only simulated the longitudinal component of the wind under neutral flow conditions in rotationally sampled space. Using Veers' original computational kernel, Kelley" expanded SNLWIND to versions that provide a mapping of the three components of the full wind vector in both Cartesian and polar coordinates as well as rotationally sampled space. In the current code, now referred to as SNLWIND-3D, the turbulence is now scaled by $u_{\text {. }}$ and the Ri rather than by turbulence intensity. This allows a wider degree of inflow conditions to be simulated including those seen over smooth, homogenous terrain, at the upwind row of a multi-row wind farm in complex terrain, and within the wind farm at row-to-row turbine spacing of 7 and 14D. It also provides simulations based on either the Kaimal or von Karman neutral-flow, stochastic spectral models as specified in various drafts of the IEC-TC88 Document, "Safety of Wind Turbine Generator Systems."

\section{AeroDvn}

Developed by the University of Utah under NREL sponsorship (Hansen ${ }^{10}$ ), the AeroDyn code consists of a series of FORTRAN subroutines for the aerodynamic analysis of horizontal-axis wind turbine generators. It was originally used in conjunction with the YawDyn simulation code, but has also been incorporated into ADAMS, and more recently, the version of the FAST2 model being used exclusively at NREL. The purpose of the AeroDyn subroutines is to simulate the aerodynamic forces seen as a result of a moving wind turbine blade through the turbulent inflow field generated by SNLWIND-3D or other inflow specification. These subroutines, in conjunction with a host dynamics code, make it possible to model the aeroelastic interactions between the blade motions and the aerodynamic forces. The routines are based on a modified bladeelement/momentum theory and also include dynamicstall and skewed-flow effects. The AeroDyn subrou- tines were used to provide the aerodynamic forces for all of the codes used in this study.

\section{YawDyn}

The YawDyn model, also developed by the University of Utah under NREL sponsorship (Hansen ${ }^{10}$ ) was developed to achieve a better understanding of the factors affecting the yaw behavior of horizontal-axis wind turbines. It is limited to a maximum of four degrees of freedom (DOF). The influence of tower motions, drive train dynamics, and blade vibration modes higher than the first flapwise are neglected. The code, using the AeroDyn subroutines, can be excited by a number of methods of introducing a time-varying wind field, including a single-point wind speed, a single-point speed plus horizontal and vertical shears, and the full-field turbulent inflow generated by SNLWIND-3D. For this analytical experiment, the three-bladed, rigid-hub turbine was modeled with fixed yaw, leaving just three DOF in the analysis (i.e., first flapwise mode for each of the three blades).

\section{FAST2}

The FAST2 model was developed by Oregon State University (Wilson, et al. ${ }^{11}$ ), under NREL sponsorship, to provide a predictive capability that included more DOF than the four available in YawDyn, but with computational times much faster than those required when using the hundreds of DOF in ADAMS modeling. Applying Kane dynamics (Wilson, et al. ${ }^{12}$ ), FAST2 simulates a teetered two-bladed, horizontal axis turbine modeled as six rigid bodies and four flexible ones. A total of 14 DOF were incorporated in the FAST2 model used by this experiment, including the following: $1^{\text {st }}$ and $2^{\text {nd }}$ blade flapwise modes, $1^{\text {st }}$ blade edgewise mode, rotor teeter, rotor rotation, drive train torsion, nacelle yaw, tower fore-aft bending ( 2 modes), and tower lateral bending (two modes) (Wright, et al. ${ }^{2}$ ). The original FAST2 code contains its own routines for calculating the aerodynamic forces and a turbulent wind simulation that consists of a deterministic contribution made up of the mean wind speed, shear, and tower interference and a random element derived from an atmospheric turbulence model that includes time varying wind direction. This experiment was conducted using a version of FAST2 that incorporates the AeroDyn subroutines, so that all of the models in the study had identical aerodynamic inputs. 


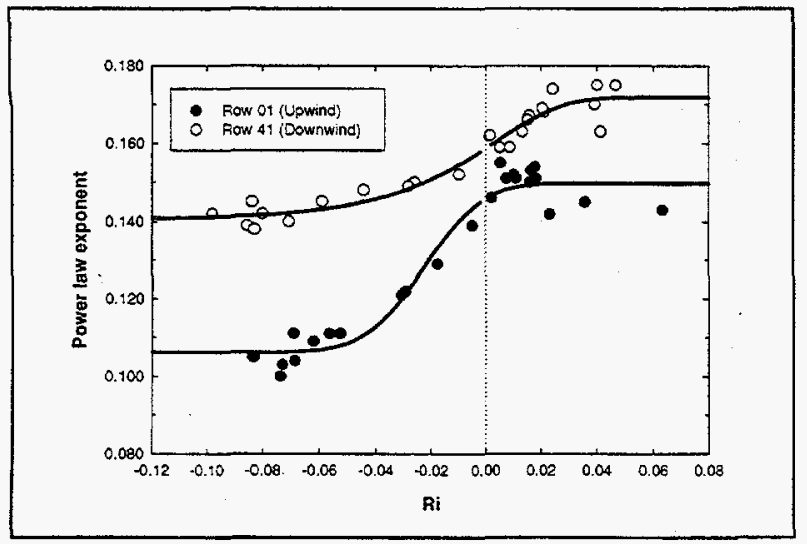

Figure 1. Variation of power law exponent with stability (Richardson number, Ri) for upwind and downwind locations.

\section{ADAMS}

ADAMS is a commercial, generalized, multi-body computational system used to develop systems dynamics models, which is available from Mechanical Dynamics, Inc., of Ann Arbor, Michigan. Under NREL sponsorship, a specialized version of ADAMS (called ADAMS/WT) with an enhanced graphical user interface was developed by Mechanical Dynamics specifically for the partially automated development of models of horizontal-axis wind turbines (Elliott and Wright ${ }^{13}$ ). ADAMS models a wind turbine as a series of rigid elements of known inertial properties that are linked via kinematic relationships and/or elastic "beams." Each of these elements has six DOF associated with it. By applying advanced equation solver and integrator methodologies, ADAMS produces timedomain solutions for system response and loads while automatically taking into account rotational effects and interactions between components. The aerodynamic excitation is linked to ADAMS through the "userwritten" SNLWIND-3D turbulent inflow via the AeroDyn subroutine package. As implemented in this study, the ADAMS model of the rigid-hub, three-bladed turbine contained 310 DOF while its two-bladed, teetered counterpart included 201 DOF.

\section{THE TURBINES SIMULATED}

The three-bladed, rigid-hub turbine simulated is a Micon 65/13, which was installed in Row 37 of a 41-row wind farm in San Gorgonio Pass, California. This stallcontrolled turbine has an upwind rotor with a

diameter of $17 \mathrm{~m}$ and was fitted with blades using airfoil shapes from the NREL Thin-Airfoil Family (Tangler, et al. ${ }^{14}$ ). The actual machine has an active yaw drive but in these simulations it was left fixed. The

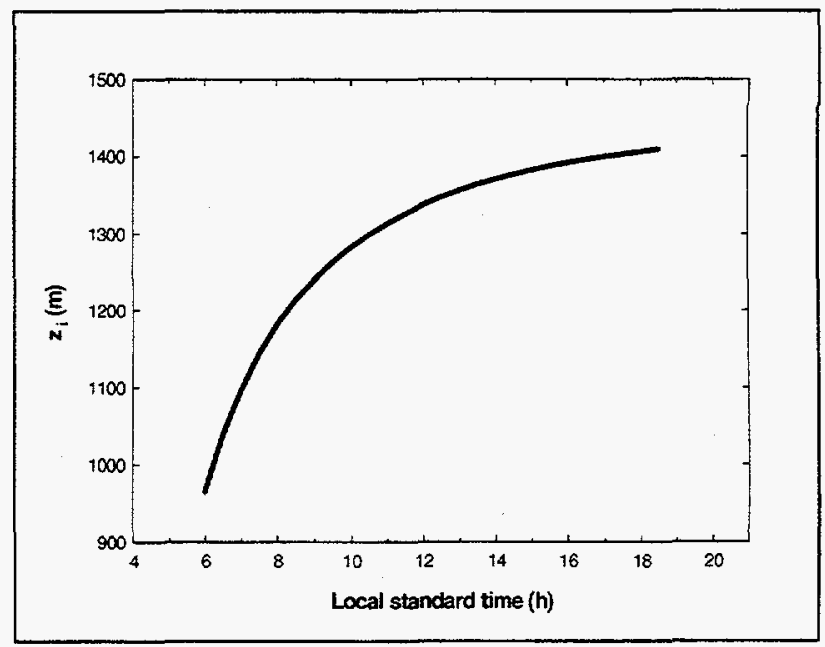

Figure 2. Variation of estimated mixed layer depth with local standard time.

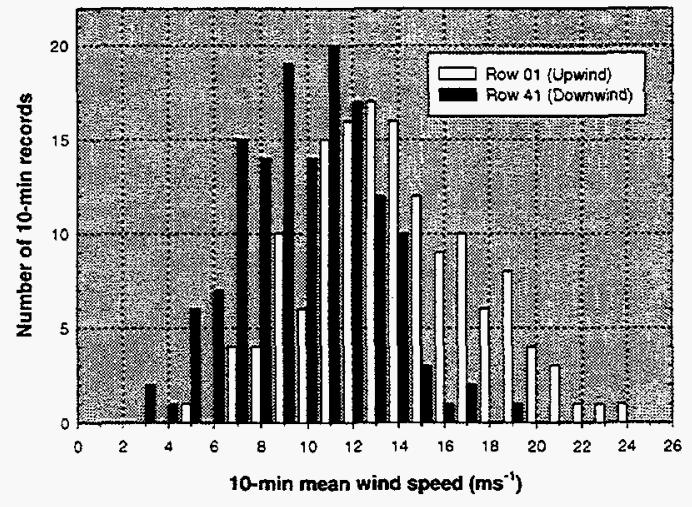

Figure 3. Simulated diurnal 10 -minute mean wind speed distributions.

YawDyn model of this turbine was developed by Laino ${ }^{1}$ and was based, in part, on the earlier ADAMS model developed by Buhl, et al. ${ }^{15}$ The ADAMS model, as implemented in this study, took advantage of the refined blade aerodynamic properties incorporated by Laino' in his modeling of the turbine. The AeroDyn subroutines for this simulation included the options of dynamic stall and inflow.

The two-bladed, teetered hub turbine model is based on a prototype with a 26.2-m diameter, stallcontrolled, downwind rotor. The turbine operates in free yaw. As installed, it was operated near the crest of a hill within a wind farm in the complex terrain of the 
Tehachapi Pass area of California. The blades used on this machine are based on airfoils derived from the NREL Thick-Airfoil Family (Tangler and Summers ${ }^{16}$ ). Neither the FAST2 or ADAMS simulations of this turbine were actually used in its design. They were assembled strictly for validation and comparison purposes. The FAST2 model is identical to the one described in Wright, et al. ${ }^{2}$. As in the case of the rigidhub turbine, the AeroDyn subroutines were applied with the dynamic stall and inflow options.

\section{INFLOW SIMULATIONS}

During the months of June, July, and August 1989, extensive boundary-layer measurements were taken from two 50-m towers installed immediately upwind of Row 01 and downwind of Row 41 of the San Gorgonio Pass wind farm. A total of 135.3 and $105.5 \mathrm{~h}$ of timecoincident record are available from the Row 01 and Row 41 towers, respectively. We calculated the distribution statistics for each of the boundary-layer turbulence-scaling parameters of hub-height mean wind speed $\left(\mathrm{U}_{\mathrm{H}}\right)$ and $\left(\mathrm{u}_{*}\right), \mathrm{Ri}$, power law exponent $(\mathrm{a})^{* *}$, and estimated mixing layer depth $\left(z_{i}\right)$ for each of the 144 , 10-minute periods contained in a diurnal cycle for each tower location. The values of the surface roughness, $z_{0}$, had been previously determined for each location.

Target values of $U_{H}$ and $R i$ for the simulation of 10minute turbulent inflow for each of the 144 periods at each position were derived by choosing a random sample from each distribution with the assumption it was normal. We found that the power law exponent was strongly correlated with the Ri parameter. The fitted relationships for arriving at a value of the power law exponent for each 10-minute simulation are shown in Figure 1. Also $u_{*}$ is strongly correlated with $\mathrm{U}_{\mathrm{H}}$. This variation is essentially linear over the range of wind speeds of interest for wind-turbine operation at the chosen locations. We derived such relationships for the variation of $u *$ with $U_{H}$ for each location and used them to establish a target value of $u_{*}$ for each period simulated. During unstable flow conditions, $(\mathrm{Ri}<0)$, the entire depth of the planetary boundary or mixed layer, $z_{i}$, is an important surface layer turbulence scaling parameter. Because this quantity was not directly measured in the field, we have estimated it using the relationship,

$$
\mathrm{z}_{\mathrm{i}} \approx 0.04 \mathrm{U}_{\mathrm{H}} / \mathrm{f}_{\mathrm{c}} \log _{10}\left(\mathrm{z}_{\mathrm{hub}} / \mathrm{z}_{\mathrm{o}}\right)
$$

where $z_{\text {hub }}$ is the hub elevation (which was chosen for convenience since it and the wind speed at that height are available in SNLWIND-3D) and the Coriolis parameter $\mathrm{f}_{\mathrm{c}}=1.46 \times 10^{-4} \sin \left(33.9^{\circ}\right.$ ) (Dutton, et al. ${ }^{17}$ ). The variation of the estimated value of $z_{j}$ with time-of-day used for simulating inflows at both locations is plotted in Figure 2. SNLWIND-3D was used to generate the 144 inflows for each location. The components of the three-dimensional wind vector were generated at a rate of 20 per second on a $6 \times 6$ Cartesian grid plus the rotor center. The grid was scaled to the particular turbine hub/rotor dimensions. A different random seed was applied for each of the individual simulations, as were the turbulence-scaling parameters representing a particular period of the day. Separate simulations were created for each location and turbine because of the differences in physical dimensions. The resulting distributions of $U_{H}$ for Rows 01 and 41 are shown in Figure 3. The diurnal variations of the actual simulated values of $U_{H}, u_{*}, R i$, and the power law exponent presented to the turbine dynamic codes are summarized in Figure 4.

\section{TURBINE SIMULATION RESULTS}

Each of the 288 simulations for the two turbines modeled using either YawDyn and ADAMS or FAST2 and ADAMS was calculated using the NWTC SGI Power Challenge $\mathrm{XL}$ computer system. This computer is configured with six central processing units and 640 megabytes of random access memory. Each YawDyn simulation of the Micon 65, with its 3 DOF, took slightly less than real time (i.e., about 9 minutes of actual clock time per simulation). In contrast, the ADAMS model, with its $310 \mathrm{DOF}$, required 5.25 hours on the average. Similarly, the teetered-hub turbine with one less rotor blade and 201 DOF with ADAMS required, on average, 4.25 hours to calculate a 10-minute record. The FAST2 code, with its $14 \mathrm{DOF}$, typically took 45 minutes to compute the same simulated time period, thus meeting one of the goals for its development.

The predicted time series for each of the three $\mathrm{Mi}$ con 65 blade root flapwise bending moments was rainflow-cycle counted over a range of -15.0 to $+40.0 \mathrm{kNm}$ with a resolution of $0.43 \mathrm{kNm}$. Similarly, the two root flapwise moments from the teetered-hub turbine were cycle counted over a range of -500 to $+500 \mathrm{kNm}$ and a resolution of $2 \mathrm{kNm}$. Only full cycles have been included.

$\because \mathrm{U}=\mathrm{U}_{1}\left(\mathrm{z} / \mathrm{z}_{1}\right)^{\mathrm{a}}$ 


\section{Micon 65 Turbine}

The YawDyn and ADAMS predicted load spectra for the Micon 65 turbine simulations are presented in Figures 5 and 6 for Rows 01 and 41 , respectively. The loads from all three blades are included, though they are not identified individually. The spectra are presented by a wind-speed class based on the 10-minute $U_{H}$ (see Kelley ${ }^{5}$ ). Class 3 includes speeds less than $9 \mathrm{~m} / \mathrm{s}$ whereas Classes 4 , 5,6 , and 7 encompass ranges of 9-11,11-13,13-15, and 15-17 $\mathrm{m} / \mathrm{s}$ respectively. Records with mean wind speeds exceeding $17 \mathrm{~m} / \mathrm{s}$ are assigned to Wind Class 8 . The number of simulated 10-minute records included in wind-class spectra are indicated in each plot.

An examination of the spectra for Row 01 in Figure 5 shows good agreement between the YawDyn and ADAMS simulations in the high-cycle region but a divergence in the important low-cycle tail. This divergence diminishes with increasing mean wind speed (loading), with very good agreement being achieved in Wind Class 8 (greater than 17 $\mathrm{m} / \mathrm{s}$ ). We believe such a divergence is the consequence of the greater number of load paths (DOF) being available in the ADAMS model. The much more turbulent conditions downwind of Row 41 are compared in Figure 5. Again, a similar degree of comparability is evident, with the closest agreement in Wind Class 8. For comparison with actual conditions, the measured load spectra for Wind Classes 3-7 from Row 37 have been included in Figure 6. One would not expect agreement with these spectra particularly in the low-cycle tail because the row-to-row spacing between turbines is only $7 \mathrm{D}$ as compared to an effective distance of $14 \mathrm{D}$ at Row 41.

We believe the differences seen in the low-cycle tails between the YawDyn and ADAMS simulations at both locations are the result of the latter model sup-

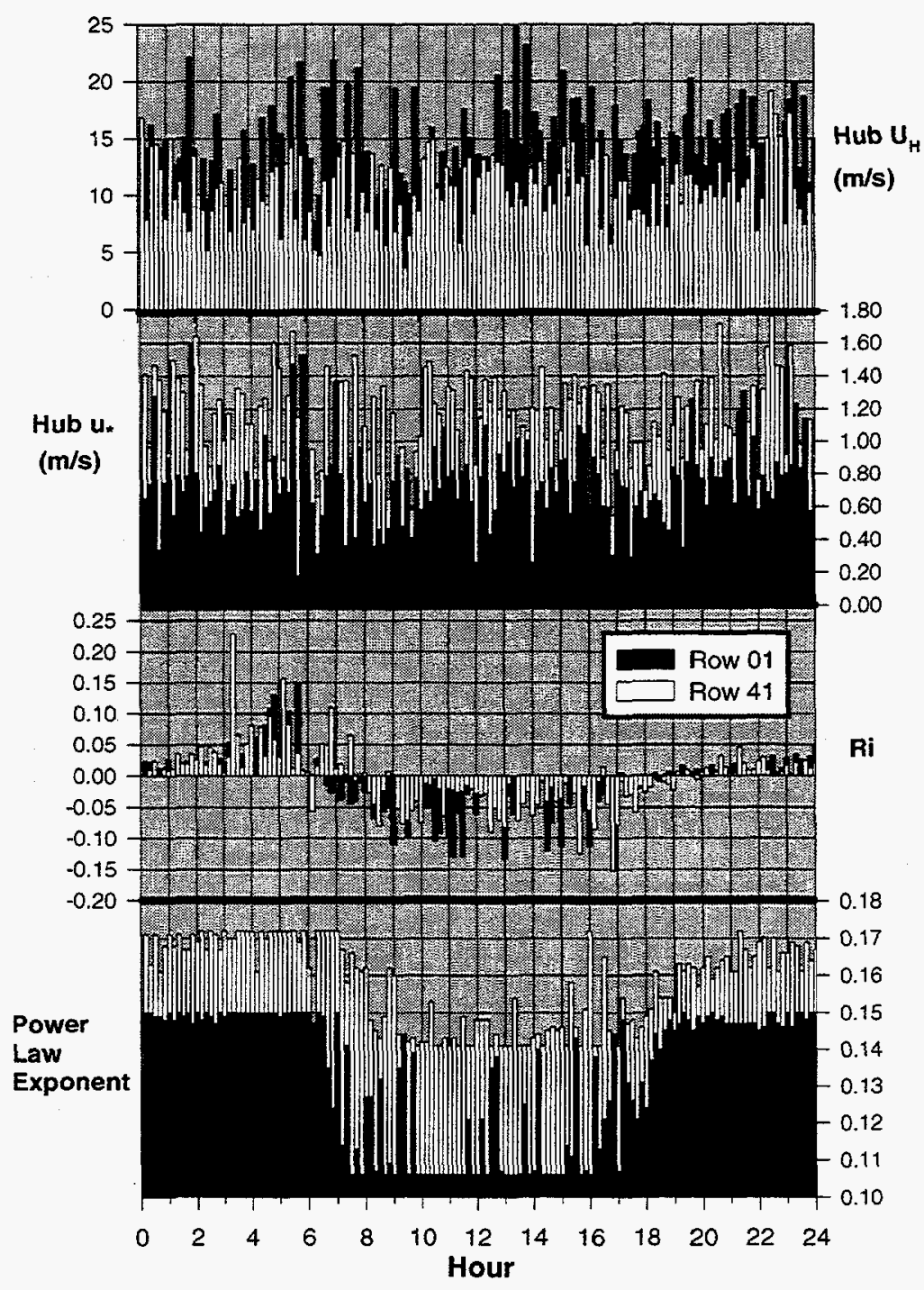

Figure 4. Diurnal variations of inflow simulation scaling parameters.

porting many additional load paths which limit the flapwise amplitudes seen at the root. It is clear, however, that the simulated load distributions reflect the exponential decay of the high loading tail of the observed data albeit at a steeper slope. This indicates that the simulated turbulent inflow provides the proper spatial and temporal characteristics in order for the simulated loads distribution to exhibit the exponential shape in the high-loading tail. To check the validity of the Row 41 simulations, we compared a subset of the 133 observed records available in Wind Class 5 at Row 37, in which the hub mean wind speed was $12.5 \pm 0.1$ 

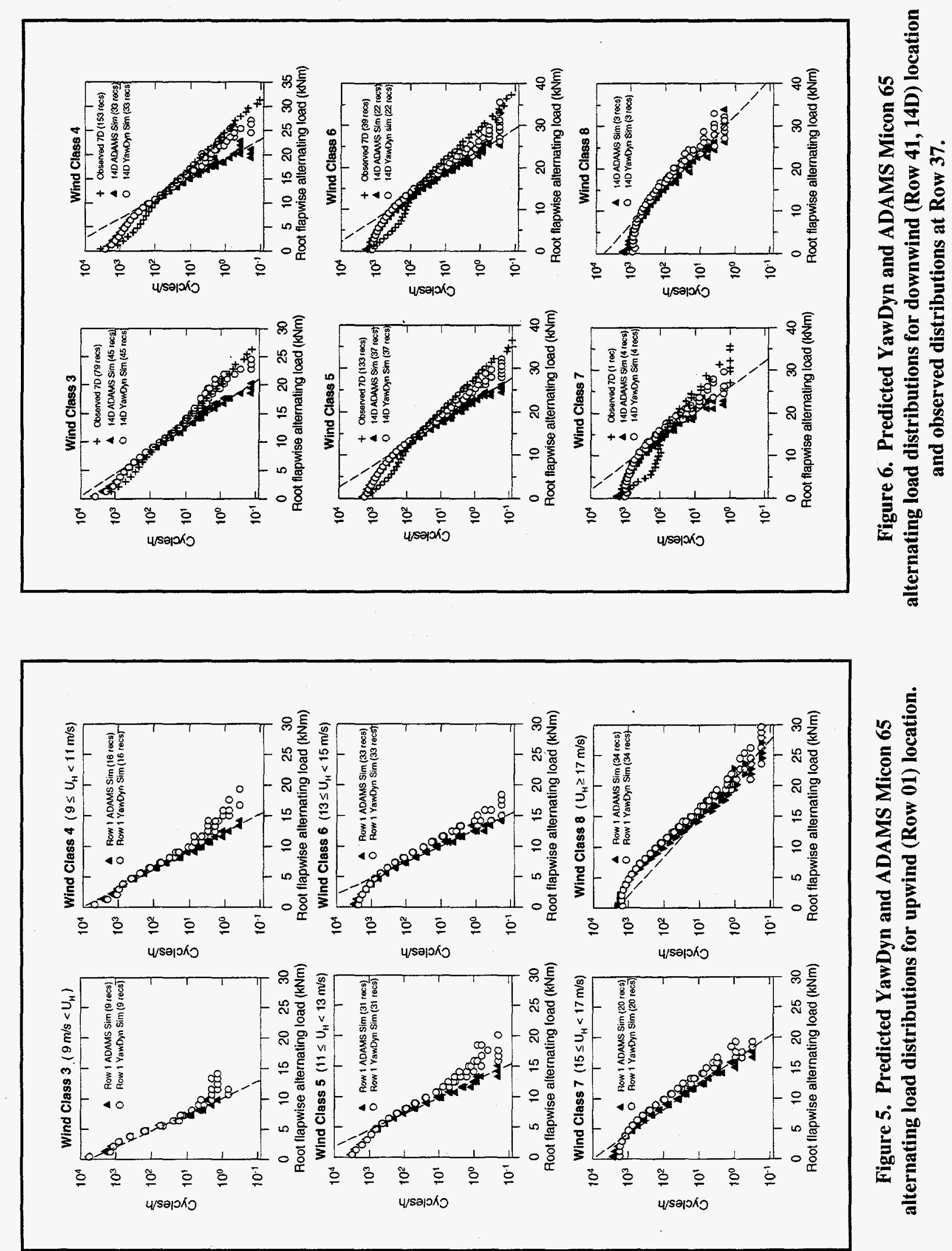


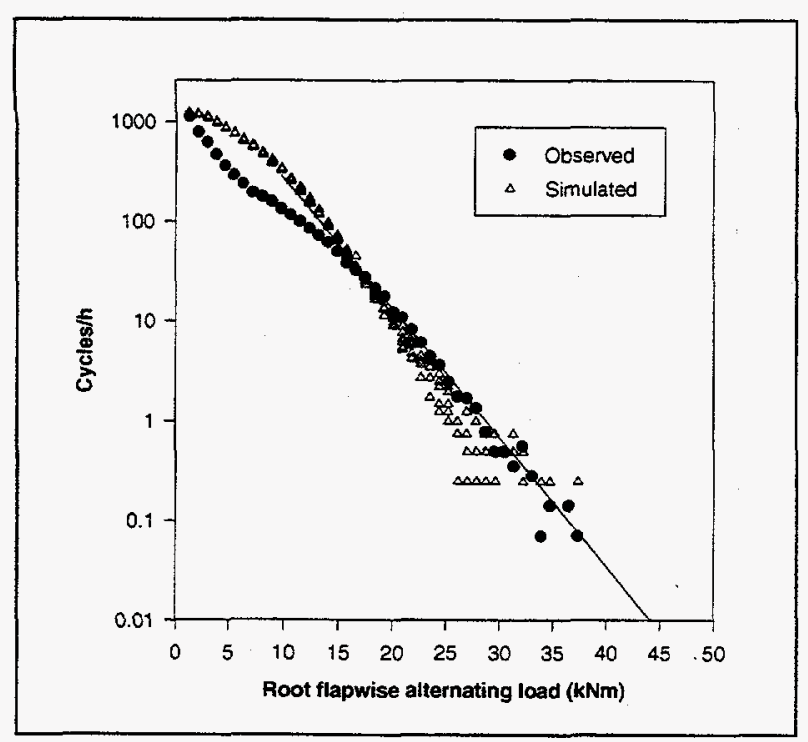

Figure 7. Comparison of observed and simulated Micon 65 root flapwise alternating load distributions for $12.5 \pm 0.1 \mathrm{~m} / \mathrm{s}$ wind speed at Row 37 .

$\mathrm{m} / \mathrm{s}$. This speed corresponds to where peak power occurs for the NREL Thin-Airfoil blades and to where considerable unsteady aerodynamic response can be expected as the outer portion of the blades cycles in and out of stall. Previously, Sutherland and Kelley ${ }^{18}$ found that operating the turbine in Wind Class 5 at this location accumulated the greatest rate of fatigue damage observed in Wind Classes 3 through 7 . We found that, for the purposes of comparison, there were a total of 14 records within this narrow speed range.

We used SNLWIND-3D to generate an inflow that was the equivalent of 14 records in length $(2.333 \mathrm{~h})$ using the Row 37-measured mean values of $\mathrm{Ri}=$ $+0.019, u_{*}=1.381 \mathrm{~m} / \mathrm{s}$, surface roughness $z_{0}=0.507 \mathrm{~m}$, and a power law exponent of 0.127 as boundary conditions for simulating conditions there. Although one specifies a "target" value of $\mathrm{u}_{*}$ to SNLWIND-3D, often the actual simulated value differs somewhat because of the unpredictable degree of stochastic cross-axis coupling of the orthogonal wind components. The more energetic and coherent the turbulence, the larger the difference. In this case we specified the observed value of $1.381 \mathrm{~m} / \mathrm{s}$; however, the actual simulated value came out to be $1.434 \mathrm{~m} / \mathrm{s}$, or $3.7 \%$ higher. We then computed the predicted flapwise loads using the Micon 65 YawDyn model for the sake of efficiency. We present the resulting alternating load spectra in Figure 7, which shows that there is reasonable agreement between the observed predicted spectra particularly in the very important LCHA tail. We believe the lower loads seen in the body of the distribution are the consequence of the

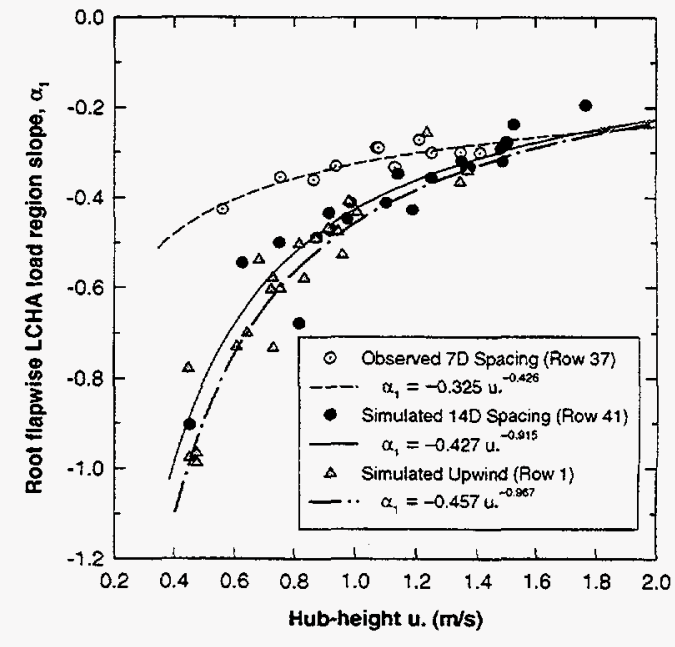

Figure 8. Variation of Micon 65 root flapwise lowcycle, high-amplitude (LCHA) region slope versus hub-height $u_{*}$ for simulated conditions at Rows 01 and 41 and observed conditions at Row 37.

actual turbine having an active yaw drive while the simulation was computed with the yaw axis held rigid. Tangler, et al. ${ }^{19}$ found that, with the yaw drive locked, the flapwise moment increased and was dominated by loads associated with a strong 4-per-revolution (4P) cyclic load superimposed on the once-per-revolution (1P) loading cycle. This $4 \mathrm{P}$ contribution to the cyclic load largely disappears (and the flapwise loading decreases) when the yaw drive is active.

Given the above, we believe the steeper slopes seen in the low-cycle, or LCHA, tail of the predicted loading spectra (particularly ADAMS), compared with those observed at Row 37, are consistent with the 14D spacing upwind of Row 41 and the 7D at Row 37. At Row 41 , the upstream turbine wakes have a greater time to evolve and reduce the degree of coherency through diffusion with the more random ambient turbulence being transported into the upstream turbine wakes both vertically and laterally. This can also be seen when one plots the slope, $\alpha_{1}$, of the exponential fit applied to the LCHA tail. In Figure 8, we compare the LCHA slopes derived from the ADAMS simulations with those observed at Row 37 as a function of hub-height $u_{*}$ in semilogarithmic coordinates. It is clear that the simulations of conditions at Rows 01 and 41 predict steeper and less damaging conditions than those at Row 37 for $\mathbf{u}$ : values up to about $1.2 \mathrm{~m} / \mathrm{s}$ (low to moderate wind speeds), however, at values above the latter the degree of expected low-cycle damage becomes similar. 


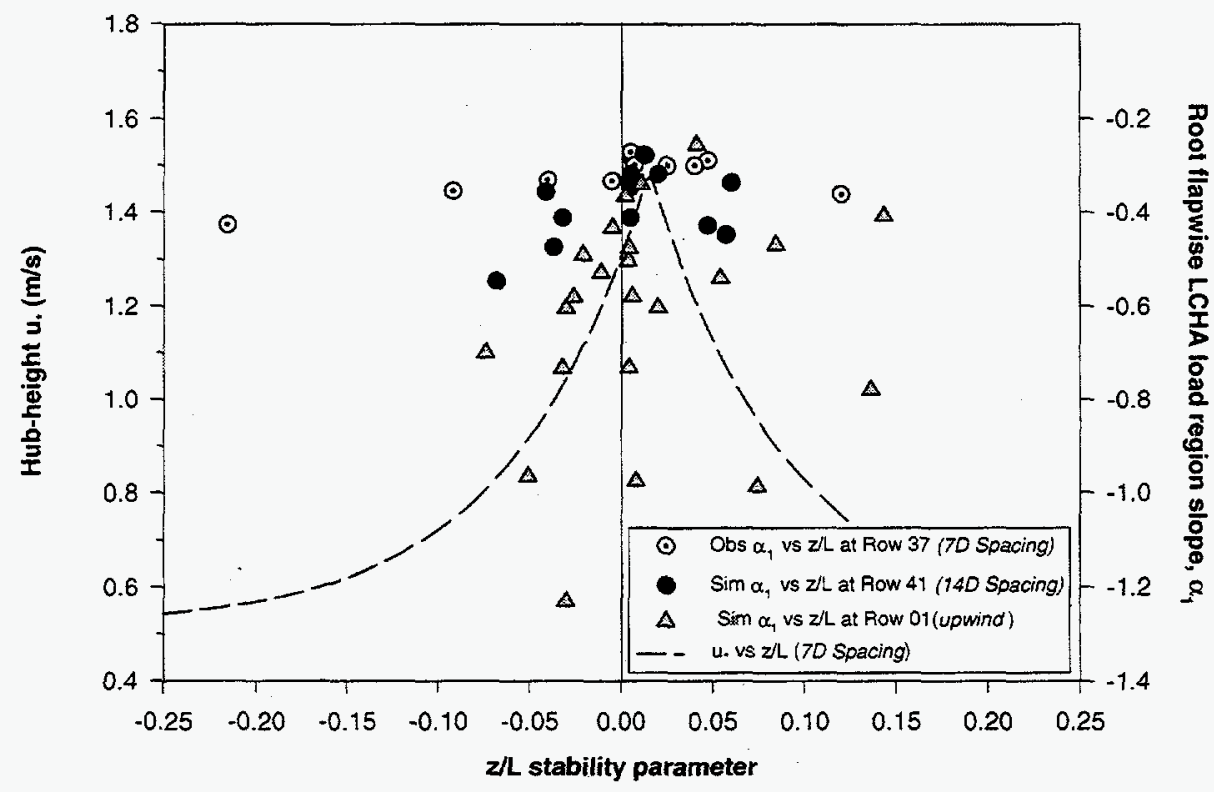

Figure 9. Variation of simulated and observed Micon 65 root flapwise LCHA slope, $\alpha_{1}$, with $\mathbf{z} / \mathbf{L}$ stability parameter.

Actual measurements will be necessary, however, to confirm the above interpretations.

Previously, Kelley ${ }^{4}$ found the degree of the LCHA slope was correlated with the hub-height or local $\mathbf{u}_{*}$ and $\mathrm{Ri}$ (or the Monin-Obukhov stability parameter $\mathrm{r}^{\frac{2}{3}}, \mathrm{z} / \mathrm{L}$, which is related to $\mathrm{Ri}$ ) for the data collected at Row 37. In Figure 9 we plot the variation of the observed value of $u *$ at Row 37 and the LCHA slopes, $\alpha_{1}$, associated with observations at Row 37 (7D spacing) and the simulated conditions at Row 4l (14D spacing). Negative $z / L$ (unstable) values are equivalent to the corresponding $\mathrm{Ri}$ ones but positive (stable) ones become increasingly larger than $\mathrm{Ri}$ as the flow becomes more stable. Using $\mathrm{z} / \mathrm{L}$ instead of $\mathrm{Ri}$ has the benefit of "stretching" the stable region of Figure 9 non-linearly, thus allowing one to more clearly see the details of the relationships of the plotted points. Figure 8 shows that it is expected that (except at the peaking behavior between stable $z / L$ values of 0 and +0.05 ) with a $14 \mathrm{D}$ spacing (Row 41) the LCHA slopes tend to become much steeper (and less damaging) than with 7D spacing (Row 37 ) as the flow stability moves away from the

\footnotetext{
$z / L$ is defined by the ratio of the geometric height, $z$. and the Obukhov length. $L$. given by $-u \cdot{ }^{3} c_{p} \rho T / g H \kappa$ where $c_{p}$ specific heat at constant pressure, $\rho$ is the air density, $H$ the vertical heat flux, and $K$ the von Karman constant $(\approx 0.4)$.
}

peak value. See Kelley ${ }^{4}$ for more discussion regarding this phenomenon. Thus, based on these simulations, one would expect the fatigue lifetime to be greater for a turbine at Row 41 than at Row 37, assuming it does not spend a disproportionate amount of time (relative to Row 37) operating within close proximity of the stability peak discussed above.

\section{Two-Bladed, Teetered-Hub Turbine}

The FAST2 and ADAMS predicted load spectra for the two-bladed, teetered-rotor turbine simulations are presented in Figures 10 and 11 for Rows 01 and 41, respectively. As before, the loads from both blades are included though they are not identified individually. Also, as before, the spectra are presented in terms of the wind from each wind speed class with the number of 10-minute records contained in each class indicated within each plot.

As seen in Figure 10, there is very good agreement between the FAST2 and ADAMS Row 01, or upwind, simulations for all but Wind Class 8 . At this writing, it is not yet clear why the discrepancy in Class 8 exists. The results of the much more energetic Row 41 simulations in Figure 11 also show very good to excellent agreement. However, there are some discrepancies in both models. For example, in Wind Class 3 the 

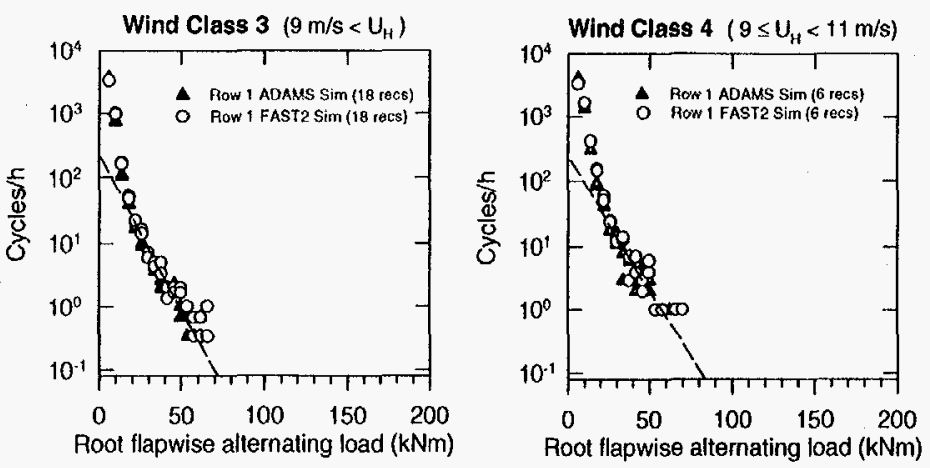

Wind Class $5\left(11 \leq U_{H}<13 \mathrm{~m} / \mathrm{s}\right)$
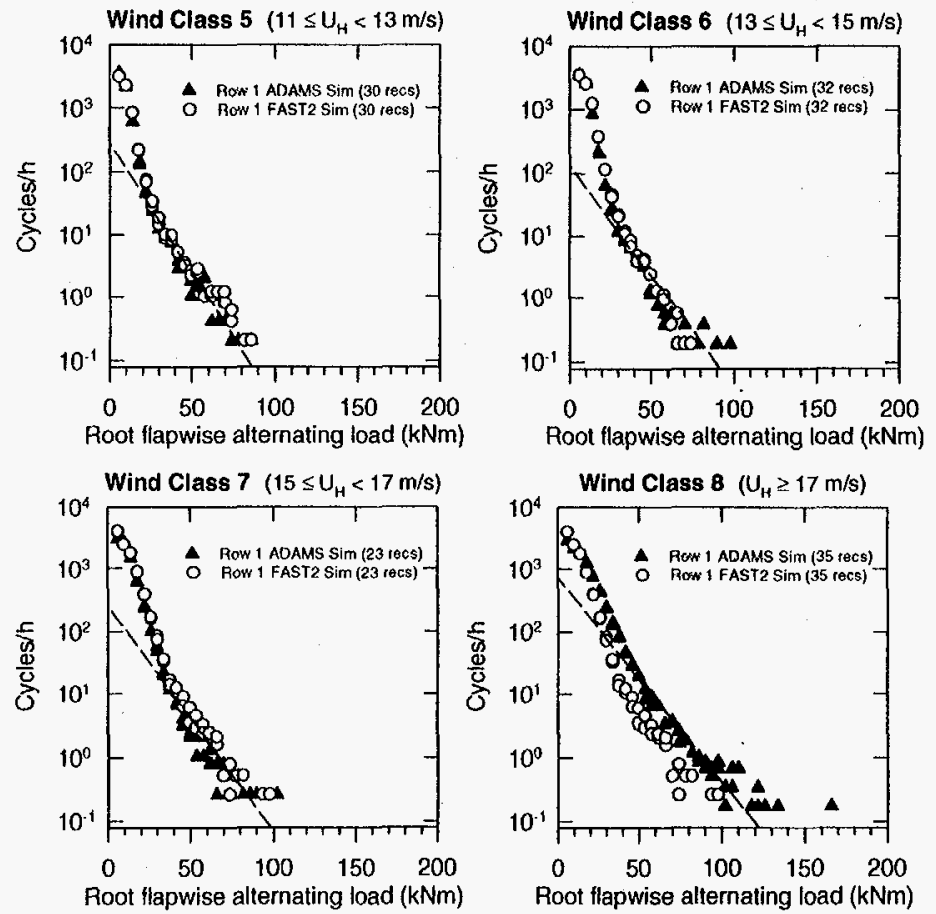

Figure 10. Predicted FAST2 and ADAMS flapwise alternating load distributions for teetered-hub turbine at the upwind (Row 01) location.

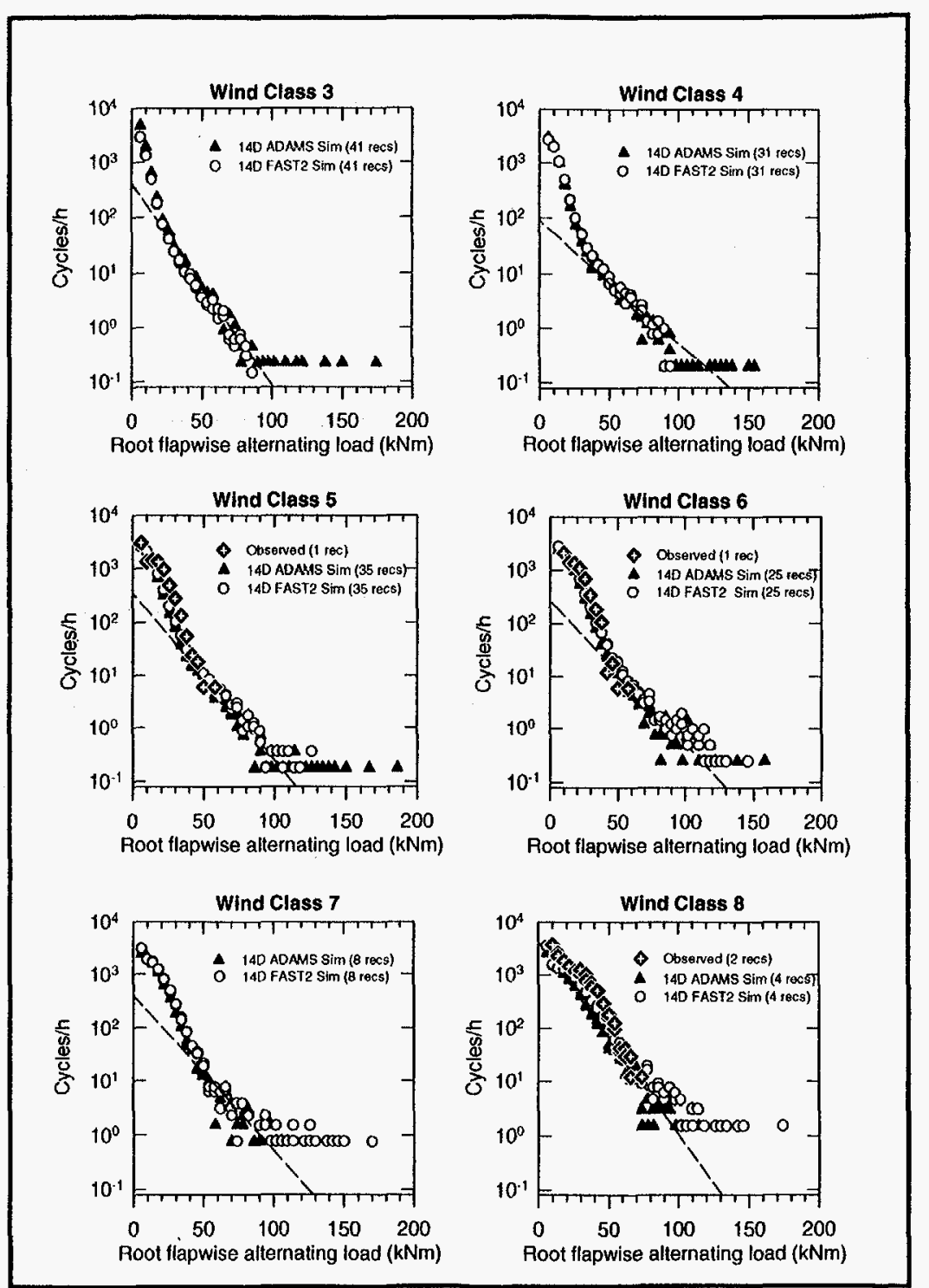

Figure 11. Predicted teetered turbine FAST2 and ADAMS flapwise alternating load distributions for downwind (Row 41, 14D) location and observed distributions from Tehachapi Pass. 
ADAMS spectrum has many large amplitude and damaging cycles indicated at the limit of the record. This is somewhat surprising because this is the lowest wind speed class. An examination of the predicted time series records revealed that these large loads are associated with computational instabilities triggered by periods of very low wind speeds. One or two of the large amplitude cycles shown in Wind Class 5 could be traced to such instabilities, however, most of those shown appear to be physically realizable. A similar situation was found with the large-amplitude cycles generated by the FAST2 code in Wind Classes 7 and 8 . However, there appears to be some form of nonnumerical instability present as well. This could be the result of running all the cases with the same time step. A smaller time step may be needed for the highest wind speed cases. The erroneous, high-loading cycles have purposely not been removed from Figure 11 in order for it to serve as an illustration of the problem.

Although we do not have any verifying observed data from San Gorgonio, we were fortunate to obtain four load records collected from a similar turbine design in the Tehachapi Pass area. The mean wind speeds of these records placed one in Wind Class 5, one in Class 6 , and two in Class 8. The turbine, from which the data was collected, was located within a wind farm with the upwind row-to-row turbine spacing greater than 7D. Where available, these load spectra have been included in the corresponding wind class plots in Figure 11. As can be seen, the agreement with these four cases is generally quite good, with even the change in slope in the neighborhood of 10 cycles/h being reproduced by the two simulations. Since we do not have any detailed measurements of the turbulent inflow characteristics, it is a possibility that these results are fortuitous. However, even if the cycle magnitudes agree by chance, the shapes of the loading distributions are generally consistent with the rigid hub turbine (i.e., the exponential decay in the high-loading tail). Though initiation of the exponential decay in the high-loading tail occurs at a lower frequency than in the rigid-hub turbine (10 cycles $/ \mathrm{h}$ versus about 100 cycles $/ \mathrm{h}$, respectively), the simulations do account for this feature being seen in the observed data. Though further confirmation is necessary, we believe the differences in overall shape distributions from this turbine compared with those associated with the rigid-hub Micon 65 are fundamental and are related to the teetering-hub DOF.

\section{CONCLUSIONS}

In this study, we have shown that the combination of an extended and properly defined inflow and a validated structural dynamics model can produce alternat- ing root flapwise load distributions that agree very well with those that are observed. Although there are some differences in the flapwise load distributions generated by the codes, it appears they all produce generally comparable results. The very good agreement in the shape of the fatigue-critical, high-loading tail of the distributions with observations suggests that the turbulent inflow simulation is reflecting both the temporal and spatial characteristics seen in actual flows.

The results of this study also suggest that, at least for predicting the root flapwise bending loads, the combination of the inflow simulation and physics contained within the structural codes can account for the dominant physical processes involved in the designs modeled. It is not clear if this level of success can be extended to much more flexible structures. There do appear to be some computational issues that need to be resolved, some of which are apparently numerical in nature; that is, issues such as computational stability, and others could be related to errors or misdefinitions in the codes themselves. In either event, although the codes seem to be useful for predicting long-term fatigue-load performance, one should critically examine the circumstances surrounding the prediction of an extreme load event.

\section{SUGGESTIONS FOR FURTHER RESEARCH}

We believe that the results of this study have given us the confidence to use simulated results to aid in developing a better understanding of the turbulence/rotor interaction, and to determine just what characteristics of the former, when coupled with the dynamics of the latter, are responsible for the highly damaging extreme events. A systematic analysis, similar to that done for the flapwise loads, should be done for the other dynamics parameters that were calculated but not analyzed. It would also be an useful exercise to recalculate the loads using the original aerodynamic routines incorporated in the FAST2 code and compare them with those arrived at using the AeroDyn routines.

The authors acknowledge that much of the interpretation that has been offered in this paper must be considered speculative because of a lack of confirming information. A series of carefully-planned measurement programs in a variety of inflow environments (i.e., downwind and within smooth and complex terrain as well as within operational, multi-row wind farms installed in both are needed. Without such information, affirmation or denial of many of the hypotheses discussed cannot be achieved. This is very important if further progress is to be made. 


\section{REFERENCES}

'Laino, D. J., and Kelley, N. D., 1995, "Investigating the Micon 65 Turbine Using YawDyn With Simulated Turbulence," Proc. WindPower '95, American Wind Energy Association, Washington, D.C.

${ }^{2}$ Wright, A. D., Kelley, N. D., and Bir, G. S., 1996 "Application of the FAST2 Code to Prediction of Fatigue Loads for Two-Bladed Teetering Hub Wind Turbines," Wind Energy, Musial, Hock, and Berg (eds.), Energy Week, January 29 to February 2, 1996, PennWell Conferences and Exhibitions, Houston, Texas, ISBN 0-9648731-7-6.

${ }^{3}$ Kelley, N. D ., 1992, "A Discussion of the Results of the Rainflow Counting of a Wide Range of Dynamics Associated with the Simultaneous Operation of Adjacent Wind Turbines," Proc. WindPower '92, American Wind Energy Association, Washington, D.C.

${ }^{4}$ Kelley, N. D., 1994, "The Identification of Inflow Fluid Dynamics Parameters That Can Be Used to Scale Fatigue Loading Spectra of Wind Turbine Structural Components," Wind Energy 1994, Musial, Hock, and Berg (eds.), SED-Vol.15, ASME.

${ }^{5}$ Kelley, N. D., 1995, "A Comparison of Measured Wind Park Load Histories with the WISPER and WISPERX Loading.Spectra," Wind Energy 1995, Musial, Hock, and Berg (eds.), SED-Vol.16, ASME.

${ }^{6}$ Winterstein, S. R. , and Lange, C. H., 1995, "Load Models for Fatigue Reliability from Limited Data," Wind Energy 1995, Musial, Hock, and Berg (eds.), SED-Vol.16, ASME.

${ }^{7}$ Kelley, N. D. and Sutherland, H. J., "Damage Estimates from Long-Term Structural Analysis of a Wind Turbine in a U.S. Wind Farm Environment," $16^{\text {th }}$ ASME/AIAA Wind Energy Symposium, in publication, 1997.

${ }^{8}$ Veers, P. S., 1988, "Three-dimensional Wind Simulation," SAND 88-0152, Sandia National Laboratory, Albuquerque, NM.

${ }^{9}$ Kelley, N. D., 1993, "Full Vector (3-D) Inflow Simulation in Natural and Wind Farm Environments Using an Expanded Version of the SNLWIND (Veers) Turbulence Code," Wind Energy 1993, S.M. Hock (ed.), SED-Vol.14, ASME.
${ }^{10}$ Hansen, A. C., 1992, "Yaw Dynamics of Horizontal Axis Wind Turbines," NREL TP-442-4822, National Renewable Energy Laboratory, Golden, CO.

11 Wilson, R. E., Freeman, L.N., and Walker, S.N., 1995, "FAST2 Code Validation," Wind Energy 1995, Musial, Hock, and Berg (eds.), SED-Vol.16, ASME.

12 Wilson, R. E., Freeman, L.N., Walker, S.N., and Harman, C.R., 1996, "FAST Advanced Dynamics Code, Two-Bladed Teetered Hub Version 2.4 User's Manual," OSU/NREL Report 96-01, National Renewable Energy Laboratory, Golden, $\mathrm{CO}$.

13 Elliott, A. S., and Wright, A. D., 1994, "ADAMS/WT: An Industry-Specific Interactive Modeling Interface for Wind Turbine Analysis," Wind Energy 1994, Musial, Hock, and Berg (eds.), SED-Vol.15, ASME.

${ }^{14}$ Tangler, J., Smith, B., Kelley, N., and Jager, D., 1992, "Measured and Predicted Rotor Performance for the SERI Advanced Wind Turbine Blades," NREL TP257-4594, National Renewable Energy Laboratory, Golden, $\mathrm{CO}$.

${ }^{15}$ Buhl, M. L., Jr., Kelley, N. D., Wright, A. D., and Osgood, R. M., 1994, "Development of a Full System Dynamics Model of the Micon 65 Wind Turbine Using ADAMS," A presentation to the Wind Energy Symposium of the 1994 ASME/ETCE Conference, January 23-26, 1994, New Orleans, LA.

${ }^{16}$ Tangler, J. and Somers, D., 1995, "NREL Airfoil Families for HAWTs," Proc. WindPower '95, American Wind Energy Association, Washington, D.C.

${ }^{17}$ Dutton, J. A., Panofsky, H. A., Larko, D., Shirer, H. N., Stone, G., and Vilardo, M., 1979, "Statistics of Wind Fluctuations Over Complex Terrain," DOE/ET/20560-1, U.S. Department of Energy, Washington, D.C.

${ }^{18}$ Sutherland, H. J., and Kelley, N. D., 1995, "Fatigue Damage Estimate Comparisons for Northern European and U.S. Wind Farm Loading Environments, "Proc. WindPower '95, American Wind Energy Association, Washington, D.C.

19 Tangler, J., Smith, B., Jager, D., McKenna, E., and Allread, J.,1989,"Atmospheric Performance Testing of the Special-Purpose SERI Thin Airfoil Family: Preliminary Results," Proc. WindPower '89, American Wind Energy Association, Washington, D.C. 